\title{
Temperature Field-Assisted Ultraviolet Nanosecond Pulse Laser Processing of Polyethylene Terephthalate (PET) Film
}

\author{
Jun $\mathrm{Xu}^{1,2}$, Youmin Rong ${ }^{1,2}\left(\right.$, Weinan Liu ${ }^{1,2}$, Tian Zhang ${ }^{1,2}$, Guoqiang Xin ${ }^{1,2}$, Yu Huang ${ }^{1,2}$ and Congyi Wu ${ }^{1,2, * \mathbb{C}}$ \\ 1 State Key Lab of Digital Manufacturing Equipment and Technology, Huazhong University of Science and \\ Technology (HUST), Wuhan 430074, China; d202080271@hust.edu.cn (J.X.); rym@hust.edu.cn (Y.R.); \\ wnliu@hust.edu.cn (W.L.); tianz@hust.edu.cn (T.Z.); gqxin@hust.edu.cn (G.X.); \\ yuhuang_hust@hust.edu.cn (Y.H.) \\ 2 School of Mechanical Science and Engineering, Huazhong University of Science and Technology (HUST), \\ Wuhan 430074, China \\ * Correspondence: cyw@hust.edu.cn
}

Citation: Xu, J.; Rong, Y.; Liu, W.; Zhang, T.; Xin, G.; Huang, Y.; Wu, C. Temperature Field-Assisted Ultraviolet Nanosecond Pulse Laser Processing of Polyethylene Terephthalate (PET) Film. Micromachines 2021, 12, 1356. https://doi.org/10.3390/mi12111356

Academic Editor: Ioanna Zergioti

Received: 30 September 2021

Accepted: 30 October 2021

Published: 2 November 2021

Publisher's Note: MDPI stays neutral with regard to jurisdictional claims in published maps and institutional affiliations.

Copyright: (c) 2021 by the authors. Licensee MDPI, Basel, Switzerland. This article is an open access article distributed under the terms and conditions of the Creative Commons Attribution (CC BY) license (https:/ / creativecommons.org/licenses/by/ $4.0 /)$.
Abstract: Understanding the mechanism of and how to improve the laser processing of polymer films have been important issues since the advent of the procedure. Due to the important role of a photothermal mechanism in the laser ablation of polymer films, especially in transparent polymer films, it is both important and effective to adjust the evolution of heat and temperature in time and space during laser processing by simply adjusting the ambient environment so as to improve and understand the mechanism of this procedure. In this work, studies on the pyrolysis of PET film and on temperature field-assisted ultraviolet nanosecond (UV-ns) pulse laser processing of polyethylene terephthalate (PET) film were performed to investigate the photothermal ablation mechanism and the effects of temperature on laser processing. The results showed that the UV-ns laser processing of PET film was dominated by the photothermal process, in which PET polymer chains decomposed, melted, recomposed and reacted with the ambient gases. The ambient temperature changed the heat transfer and temperature distribution in the laser processing. Low ambient temperature reduced the thermal effect and an increase in ambient temperature improved its efficiency (kerf width: $39.63 \mu \mathrm{m}$ at $-25^{\circ} \mathrm{C} ; 48.30 \mu \mathrm{m}$ at $0{ }^{\circ} \mathrm{C} ; 45.81 \mu \mathrm{m}$ at $25^{\circ} \mathrm{C} ; 100.70 \mu \mathrm{m}$ at $100{ }^{\circ} \mathrm{C}$ ) but exacerbated the thermal effect.

Keywords: laser processing; PET film; transparent polymer; temperature field; ultraviolet nanosecond pulse laser; laser photothermal ablation

\section{Introduction}

Polymer films are widely applied in electronic devices [1], flexible devices [2], energy devices [3], etc. [4,5], due to their unique physical and chemical properties. Thus, high-precision processing methods for polymer films have received increasing attention. In particular, the rapid development of large-scale integrated circuits and various functional elements has created higher requirements for the processing precision, quality and efficiency of polymer films. Laser processing, as a non-contact processing method, has received growing attention due to its adaptability, low divergence and ability to render the selective removal of polymers with high spatial resolution [6,7], and it is widely applied in the processing of a variety of materials such as metals, glasses, polymers, etc. [8-12] Therefore, the high-precision laser processing of polymer films has attracted much attention due to its unique advantages [12]. In past decades, many polymers have been studied for laser micromachining such as polyethylene terephthalate (PET) [13], polyimide (PI) [14], polydimethylsiloxane (PDMS) [15], polymethyl methacrylate (PMMA) [16], polytetrafluoroethylene (PTFE) [17], etc. [4,18] However, questions regarding the improvement of the precision, quality and efficiency of laser processing, as well as the laser ablation process and mechanism, still prevail. 
According to the principles of laser processing and previous research,, there are three ways to improve the procedure by changing the interactions between lasers and materials: (1) adjusting the parameters of lasers, such as power, wavelength, pulse width, etc. [19,20] (2) adjusting the physical or chemical properties of materials, such as absorption coefficient, reflectivity, thermal conductivity, etc. [21-23] (3) adding physical fields or changing the external chemical environment such as temperature field, electromagnetic field, supersonic wave or specific chemical solutions [24,25]. Adjusting the laser parameters is an effective method to improve processing quality, but its effectiveness is limited in certain materials. Furthermore, although changing the material properties can bring some improvement, usually this change is irreversible and difficult for the formed polymer films. Compared with the above two methods, adding physical fields or changing the external chemical environment is more simple, effective and widely applicable.

The laser ablation process of polymer films is a combination of photothermal and photochemical processes [26]. Between these two mechanisms, the photothermal mechanism plays an important role in laser processing, especially for transparent polymer films with poor absorption. Therefore, the absorption, conversion and transfer of heat, as well as the change and distribution of temperature, affect the ablation and decomposition of polymer films during laser processing in important ways. This is key to correctly managing the evolution of heat and temperature in time and space during the laser processing of polymer films via simple adjustments to the ambient environment, so as to improve the procedure. It also helps to understand the process and mechanism of the laser processing of polymer films.

In this study, an external temperature field was applied to assist the laser processing of polymer films to investigate the effects of ambient temperature on the procedure, which made the laser ablation mechanism clearer and more understandable. The selected experimental material was PET film, which is widely used in both the electronics industry and daily life $[27,28]$. The applied laser was an ultraviolet $(355 \mathrm{~nm})$ nanosecond (UV-ns) pulse laser due to it being less expensive and possessing an appropriate wavelength for polymer. Firstly, thermogravimetric analysis (TGA), thermogravimetric analysis, Fourier transform infrared spectroscopy (TGA-FTIR), pyrolysis-gas chromatography-mass spectrometry (GCMS) and Raman spectrometry were performed to study the thermal decomposition process and laser photothermal ablation mechanism of PET films. Secondly, laser processing experiments (single-spot ablation and line ablation) of PET films at various ambient temperatures $\left(-25^{\circ} \mathrm{C}, 0{ }^{\circ} \mathrm{C}, 50^{\circ} \mathrm{C}, 75^{\circ} \mathrm{C}, 100^{\circ} \mathrm{C}\right)$ were performed to investigate the effects of ambient temperature on the morphology and geometric characteristics (size, processing area, heat affected zone (HAZ)) of features (hole and kerf) so as to study the influencing mechanism of ambient temperature on the laser processing of PET film. The results showed that the laser processing of PET film was dominated by the photothermal decomposition process, in which PET polymer chains decomposed, melted, recomposed and reacted with the ambient gases. Changes in ambient temperature affected the laser processing of PET film: an increase in ambient temperature changed the heat transfer and temperature distribution during the laser processing, while a lower ambient temperature reduced the thermal effect. Increasing ambient temperature also improved the efficiency (kerf width: $39.63 \mu \mathrm{m}$ at $-25^{\circ} \mathrm{C} ; 45.81 \mu \mathrm{m}$ at $25^{\circ} \mathrm{C} ; 100.70 \mu \mathrm{m}$ at $100{ }^{\circ} \mathrm{C}$ ) but exacerbated the thermal effect. This work provides effective methods to study the laser processing mechanism of polymer films, as well as an approach to improve this procedure.

\section{Materials and Methods}

\subsection{Materials}

The raw material that was processed was commercial transparent PET film (Thickness: $0.2 \mu \mathrm{m}$ ), supplied by Xilu Photoelectricity Technic CO., LTD (Shenzhen, China). 


\subsection{Laser Processing System}

The laser processing system used was an experimental platform built by the team. As shown in Figure 1a, the laser processing system consisted of an ultraviolet nanosecond (UVns) laser (Poplar-355-15A5, Wuhan Huaray Precision Laser Co. Ltd., Wuhan, China), two reflectors, a three-dimensional scanning galvanometer (intelliSCAN 14, Scanlab, Puchheim, Germany), a beam expander, a proportion-integral-differential (PID) temperature control platform and a computer. The output power of the laser was controlled by adjusting laser repetition frequency and measured with a power meter. The specific parameters of the laser processing system are listed in Table 1. PET film samples were placed on the PID temperature control platform, the surface temperature of which was regulated by either ceramic heater heating or liquid nitrogen cooling. UV-ns laser, scanning galvanometer and the PID temperature control platform were controlled by computer so that laser processing parameters (laser power, scanning speed and ambient temperature) could be adjusted.
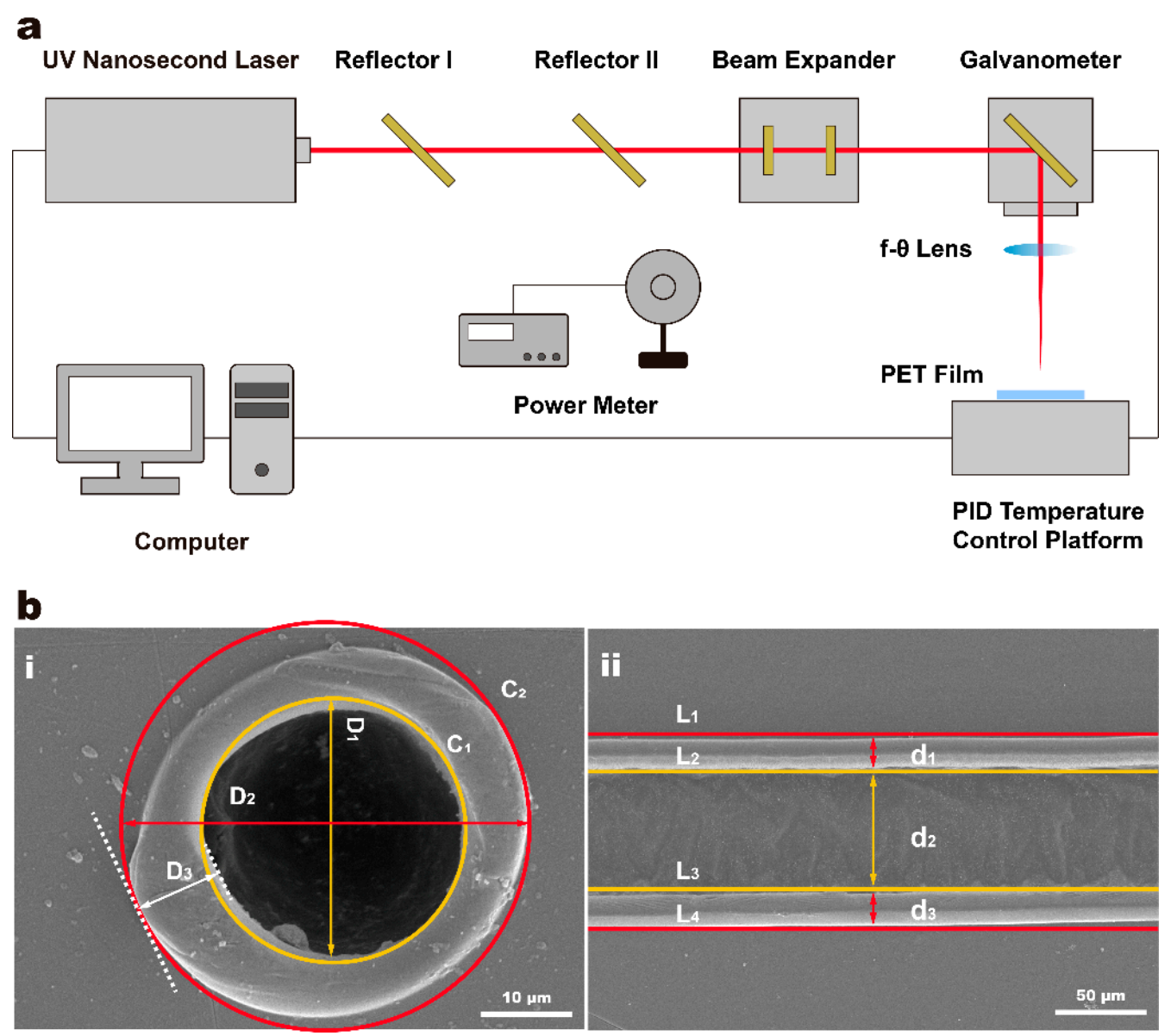

Figure 1. The Schematic diagram of the laser processing of PET film (a), and the processing quality evaluation (b) of different features (hole (i) and kerf(ii)).

Table 1. The specific parameters of laser processing system.

\begin{tabular}{cc}
\hline Parameters & Values \\
\hline Wavelength & $355 \mathrm{~nm}$ \\
Pulse width & $16 \pm 2 \mathrm{ns@50} \mathrm{kHz}$ \\
Beam diameter & $>11.8 \mu \mathrm{m}$ \\
Focal length & $167 \mathrm{~mm}$ \\
\hline
\end{tabular}




\subsection{Experimental Design}

Photothermal ablation and thermal effects play important roles in laser processing. Heat generation and transfer can be regulated by adjusting processing parameters (laser power, scanning speed, scanning times, etc.), material properties or environmental conditions. In our experimental design, in order to investigate the influences of ambient temperature on heat generation and transfer during laser processing, single-point and line laser processing were performed. In these experiments, processing parameters (laser power, repetition frequency, duration time, scanning times, etc.) were constant and the effects of ambient temperature were investigated by temperature gradient experiments. Table 2 shows the levels of ambient temperature and processing parameters in the single-point and line laser processing experiments.

Table 2. The experimental design.

\begin{tabular}{cccc}
\hline Experiment & No. & Temperature $\left({ }^{\circ} \mathbf{C}\right)$ & Parameters \\
\hline & 1 & -25 & \\
Single-Point & 2 & 0 & Laser Power $=0.9 \mathrm{~W}$ \\
Laser Processing & 3 & 25 & Repetition Frequency $=200 \mathrm{kHz}$ \\
& 4 & 50 & Duration Time $=0.05 \mathrm{~s}$ \\
& 5 & 75 & \\
Line & 6 & 100 & Laser Power $=0.9 \mathrm{~W}$ \\
Laser Processing & 1 & -25 & Repetition Frequency $=200 \mathrm{kHz}$ \\
& 2 & 0 & Scanning Speed $=50 \mathrm{~mm} / \mathrm{s}$ \\
& 4 & 25 & Scanning Times $=30$ \\
\hline
\end{tabular}

Based on the typical features (hole and kerf) of PET film samples after laser processing, processing quality evaluation methods were established. As shown in Figure 1b, in the single-point laser processing experiment, edge profiles of ablation hole circles $C_{1}$ with diameter $D_{1}$ and $C_{2}$ with diameter $D_{2}$ were clearly observed. HAZ was located between $C_{1}$ and $C_{2}$ with spacing of $D_{3}$, the bump formed after PET melting and solidification. In the line laser processing experiment, edge profiles of ablation kerf lines $\mathrm{L}_{1}, \mathrm{~L}_{2}, \mathrm{~L}_{3}$ and $\mathrm{L}_{4}$ could be clearly observed. Among them, HAZ above kerf was located between $\mathrm{L}_{1}$ and $\mathrm{L}_{2}$ with spacing of $d_{1}$. Kerf was located between $L_{2}$ and $L_{3}$ with spacing of $d_{2}$. HAZ below kerf was located between $L_{3}$ and $L_{4}$ with spacing of $d_{3}$. The values of hole diameter $\left(D_{H}\right)$, processing area diameter of hole $\left(\mathrm{D}_{\mathrm{PH}}\right), \mathrm{HAZ}$ width of hole or bump $\left(\mathrm{D}_{\mathrm{HH}}\right.$, maximum) and kerf width $\left(W_{K}\right)$ were initialized as the values of $D_{1}, D_{2}, D_{3}$ and $d_{2}$, respectively. HAZ width of kerf $\left(\mathrm{W}_{\mathrm{HK}}\right)$ and processing area diameter of kerf $\left(\mathrm{W}_{\mathrm{PK}}\right)$ were calculated using the following equations:

$$
\begin{aligned}
\mathrm{W}_{\mathrm{HK}} & =\operatorname{MAX}:\left(\mathrm{d}_{1}, \mathrm{~d}_{3}\right) \\
\mathrm{W}_{\mathrm{PK}} & =\mathrm{d}_{1}+\mathrm{d}_{2}+\mathrm{d}_{3}
\end{aligned}
$$

\subsection{Characterizations}

A scanning electron microscope (SEM, HITACHI SU3900, Tokyo, Japan) was applied to observe surface morphologies of the kerf and hole of PET film samples. A thermogravimetry-infrared association meter (TGA-FTIR, PerkinElmer, Waltham, MA, USA) was used for the thermogravimetric analysis (TGA, $25-1000{ }^{\circ} \mathrm{C}$ ) of PET film, and IR spectra (500-4000 $\mathrm{cm}^{-1}$ ) of gaseous decomposition products of PET film at different temperatures were collected during thermal decomposition process. A pyrolysis-gas chromatography-mass spectrometer (GC-MS, Agilent 7890A/5975C, Santa Clara, CA, USA) was used to analyze gaseous decomposition products of PET film during rapid pyrolysis $\left(25-1000{ }^{\circ} \mathrm{C}, 50{ }^{\circ} \mathrm{C} / \mathrm{ms}, \mathrm{N}_{2}\right)$. A laser confocal Raman spectrometer $\left(532 \mathrm{~nm}, 500-3000 \mathrm{~cm}^{-1}\right.$, 
LabRAM HR800, Horiba JobinYvon, Palaiseau, France) was used for the Raman spectra of PET film and its solid decomposition products.

\section{Results and Discussion}

\subsection{Laser Ablation Mechanism of PET Film}

During the laser processing of polymers, laser ablation is a combination of photothermal and photochemical processes [26,29]. Between these two mechanisms, the photothermal mechanism plays an important role in laser processing, especially for transparent polymers with poor absorption. It is important and effective to analyze the laser ablation products during photothermal ablation in order to understand how the laser ablation of polymers works, as well as improving its quality. Therefore, thermogravimetric analysis was performed to analyze the thermal decomposition process of the PET film. Figure 2 shows the TGA-DTG curves of PET film. The thermal decomposition process of the PET film consisted of two steps. First, when the temperature reached about $310.5^{\circ} \mathrm{C}$, the PET film started to decompose and its weight dropped to about $40.7 \%$. Second, when the temperature reached about $475.0{ }^{\circ} \mathrm{C}$, the PET film further decomposed and its residue weight was about $10.6 \%$.

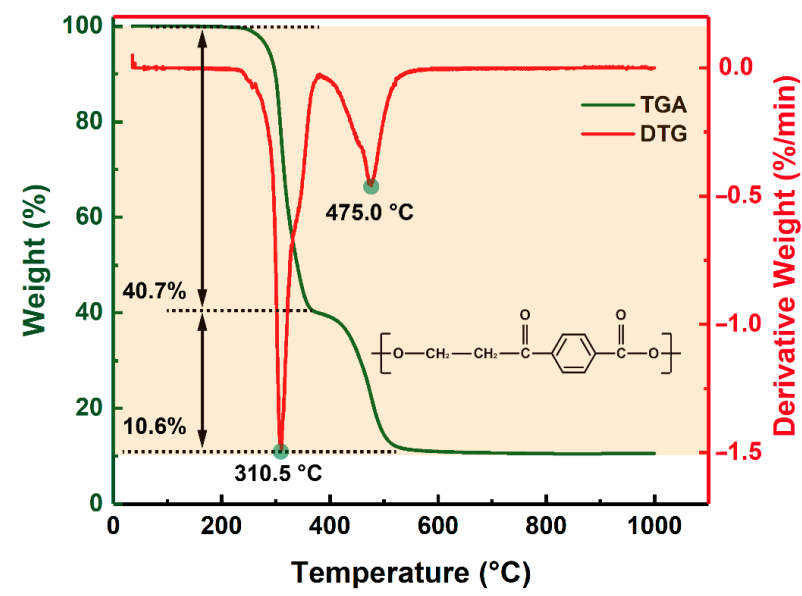

Figure 2. TGA-DTG curves of the PET film.

After this, pyrolysis-gas chromatography-mass spectrometry was performed to analyze the gaseous decomposition products of the PET film during pyrolysis. Figure 3 shows the ion current of evolved gases during its pyrolysis. The results showed that the gaseous decomposition products produced during the pyrolysis of the PET film were mainly composed of: carbon dioxide (3.90\%); 1-phenyl-1,2-propanedione $(4.65 \%)$; benzoic acid (12.56\%); o-diacetylbenzene (3.90\%); benzimidazole-2-carboxaldehyde (11.56\%); 1-methyl-, oxime 4-acetylbenzoic acid (26.17\%); 2,4,5-triphenyl-1,3-oxazole (11.67\%); (4-dimethylamino-phenyl)-(4-nonyloxy-phenyl)-methanone (4.28\%); etc. Table 3 lists the information about the gaseous decomposition products of the PET film in detail. These results showed that during the pyrolysis process, the PET film either decomposed into small, molecular-like carbon dioxide, or recomposed to form new substances such as 2,4,5triphenyl-1,3-oxazole. Ambient gases also participated in the pyrolysis process of the PET film. During the laser processing of the PET film, the decomposition process and products of the PET film were more complicated, clearly due to the more complex environment and the more complex interactions between laser, heat and matter. 
Table 3. Composition table of the evolved gaseous products during pyrolysis of PET film.

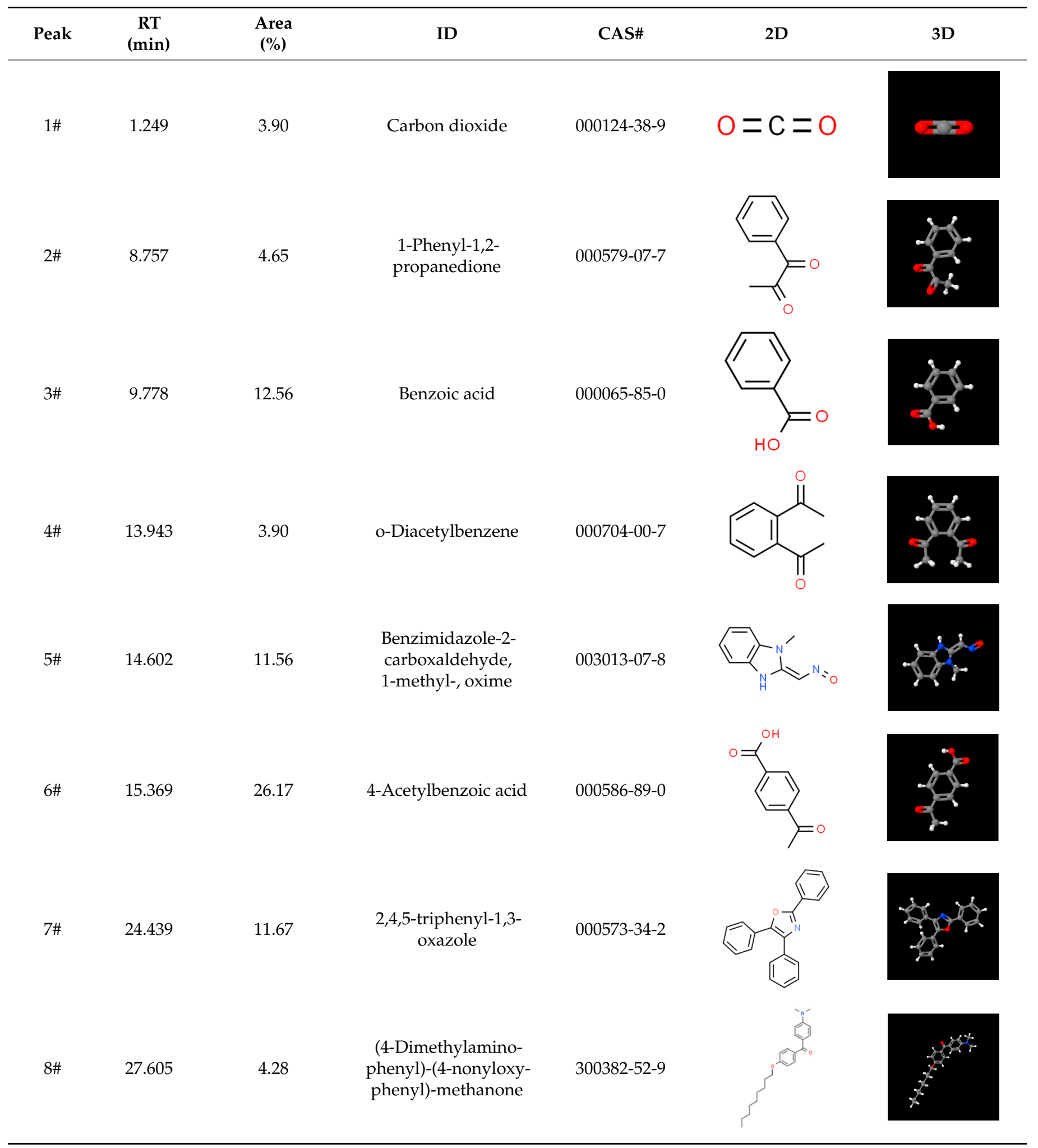

Furthermore, TGA-FTIR was used to analyze gaseous decomposition products formed during the pyrolysis of the PET film. FTIR spectra of gaseous products at different temperatures from 50 to $1000{ }^{\circ} \mathrm{C}$ are presented in Figures 4 and 5. There was no obvious absorption peak below about $300{ }^{\circ} \mathrm{C}$, which meant no decomposition. Above $300{ }^{\circ} \mathrm{C}$, obvious absorption peaks gradually appeared and the intensity reached its maximum at 
$325^{\circ} \mathrm{C}$ and $489^{\circ} \mathrm{C}$ (Figure 5a), respectively, which indicated that the PET film began to decompose gradually and was consistent with the thermal analysis results. As shown in Figure $5 \mathrm{~b}$, the characteristic peaks of carbon dioxide $\left(674 \mathrm{~cm}^{-1}\right.$ and $\left.2342 \mathrm{~cm}^{-1}\right)$, phenyl $\left(1192 \mathrm{~cm}^{-1}\right.$ for $\mathrm{C}-\mathrm{H}, 1486 \mathrm{~cm}^{-1}$ for $\left.\mathrm{C}=\mathrm{C}\right)$ and carbonyl group $\left(1730 \mathrm{~cm}^{-1}\right.$ for $\left.\mathrm{C}=\mathrm{O}\right)$ were observed in the gaseous products at $325^{\circ} \mathrm{C}$, which might be due to the formation of small molecules such as carbon dioxide and benzoic acid. The peaks at $2822 \mathrm{~cm}^{-1}$ and $2954 \mathrm{~cm}^{-1}$ were assigned to $\mathrm{CH}_{\mathrm{x}}$ stretching vibrations [30,31]. At $489^{\circ} \mathrm{C}$, a stronger $\mathrm{C}-\mathrm{H}$ characteristic peak was observed at $2936 \mathrm{~cm}^{-1}$. When the temperature rose above $996^{\circ} \mathrm{C}$, the PET film further decomposed and recomposed into small molecules. Here, the characteristic peaks of carbon nitrogen compounds $\left(1132 \mathrm{~cm}^{-1}\right.$ for C-N, $2108 \mathrm{~cm}^{-1}, 2182 \mathrm{~cm}^{-1}$ and $2360 \mathrm{~cm}^{-1}$ for $\mathrm{C} \equiv \mathrm{N}$ ) and carbon oxides ( $1342 \mathrm{~cm}^{-1}$ for $\mathrm{C}-\mathrm{O}$ ) appeared, but the characteristic peaks of phenyl and carboxyl groups did not, which indicated the PET film not only decomposed, but also recomposed and even reacted with ambient gases under high temperature. These FTIR results at different temperatures were consistent with the pyrolysis results.

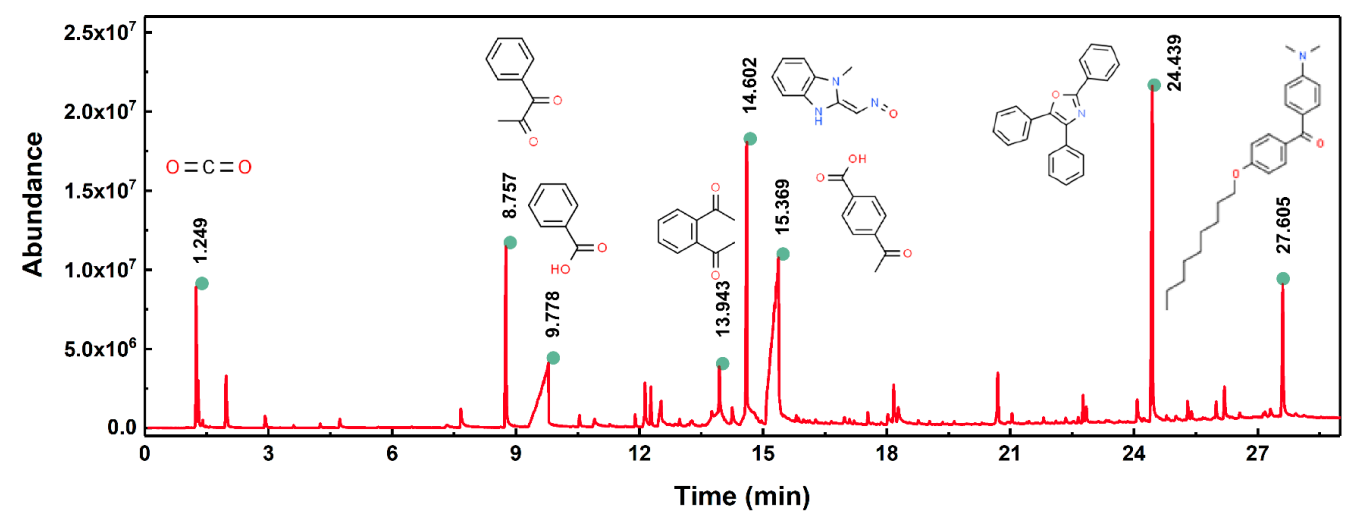

Figure 3. Ion current of evolved gaseous products during pyrolysis of PET film.

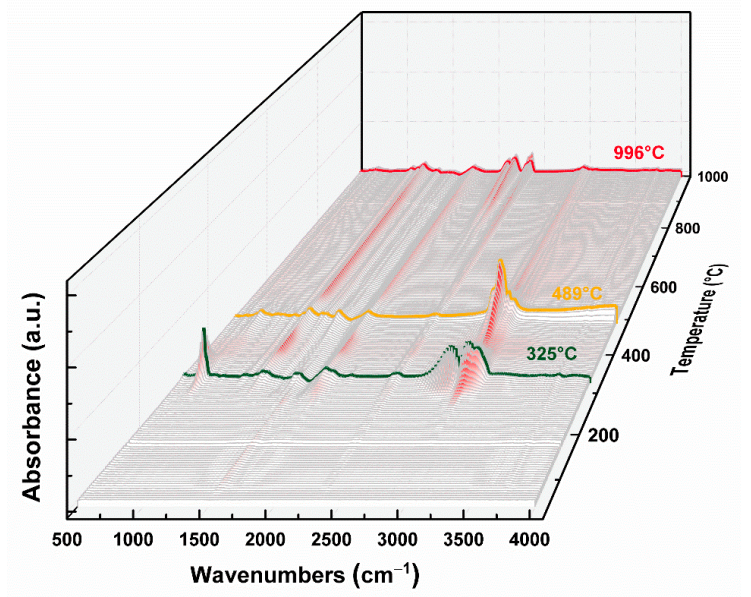

Figure 4. Infrared spectrogram of evolved gaseous products during pyrolysis of PET film.

In addition to the gaseous decomposition products, the solid residues after laser ablation were analyzed by a Raman spectrometer. Figure 6 shows the Raman spectra of different areas of the PET film after laser processing: the unprocessed area of the native PET film (Point 1); the outer edge of the bump (Point 2); the surface of the bump (Point 3); and the inner surface of the kerf, or inner edge of the bump (Point 4). The Raman spectrum of the PET film was consistent with previous reports [32], in which characteristic peaks of terephthalate and of ethylene glycol $\left(\mathrm{CH}_{2}-\mathrm{CH}_{2}-\mathrm{O}\right)$ functional groups were found. In detail, the characteristic peaks at $632 \mathrm{~cm}^{-1}$ (CCC in plane bending (phenyl)), $796 \mathrm{~cm}^{-1}$ (C-H out of plane bending (phenyl)), $860 \mathrm{~cm}^{-1}$ (C-C stretching (phenyl breathing), $\mathrm{C}-\mathrm{O}$ 
stretching), $1095 \mathrm{~cm}^{-1}$ (C-C stretching (glycol)), $1118 \mathrm{~cm}^{-1}$ (C-H in plane bending (phenyl), C-O stretching), $1187 \mathrm{~cm}^{-1}$ (C-H in plane bending (phenyl)), $1292 \mathrm{~cm}^{-1}$ (C-C stretching (phenyl), C-O stretching), $1416 \mathrm{~cm}^{-1}$ (C-C stretching (phenyl)), $1615 \mathrm{~cm}^{-1}(\mathrm{C}=\mathrm{C}$ stretching (phenyl)) and $1726 \mathrm{~cm}^{-1}$ ( $\mathrm{C}=\mathrm{O}$ stretching) were observed in the Raman spectrum of the PET film (Point 1) [32]. After laser ablation, a kerf, a bump and splashes were observed in the laser processing area due to the melting of the PET film caused by heat. At Points 2, 3 and 4 , the characteristic peak intensity of the functional groups in the PET film decreased to varying degrees, and the closer these were to the central laser processing area, the lower their intensity, and in some cases they even vanished. This indicated that during the laser processing of PET film, the polymer chains absorbed enough heat to cause their bonds to break and decompose into small molecular fragments, due to the photothermal mechanism. The closer to the processing center, the higher the temperature and the more complete the decomposition of the polymer chains was.

a

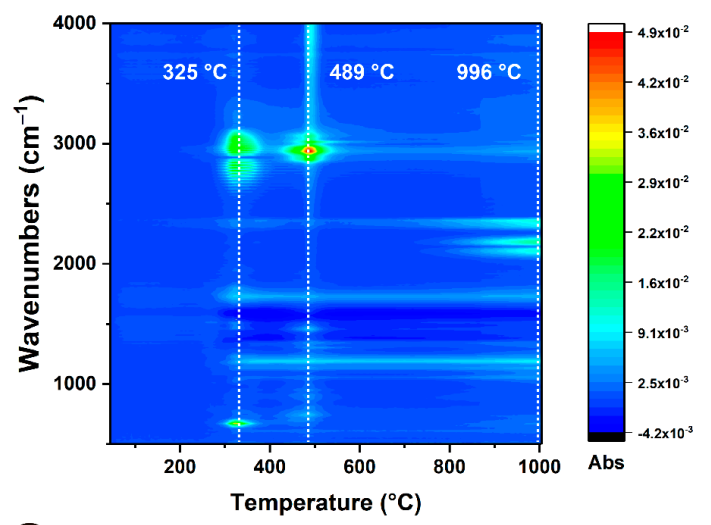

C

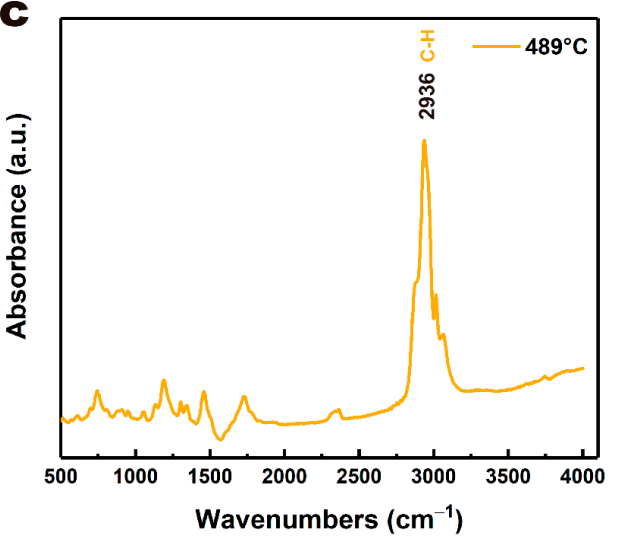

b
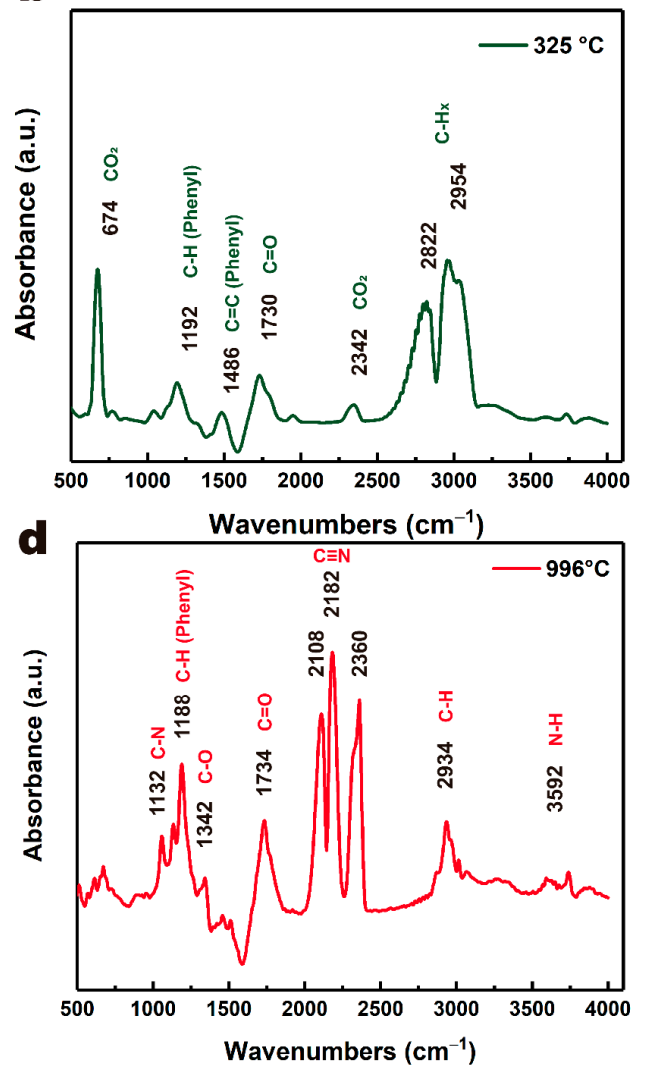

Figure 5. Infrared spectral intensity maps of evolved gaseous products during pyrolysis of PET film (a), and infrared spectrogram at typical temperatures: (b) $335^{\circ} \mathrm{C}$, (c) $489{ }^{\circ} \mathrm{C}$ and (d) $996{ }^{\circ} \mathrm{C}$.

According to the above results, showing gaseous products caused by thermal decomposition and solid products caused by laser ablation of the PET film, the laser processing process and mechanism of the PET film were clear. Figure 7 illustrates the schematic diagram of the interaction mechanism between nanosecond UV laser and the PET film during laser processing. Firstly, the PET film was almost transparent at the laser excitation wavelength $(355 \mathrm{~nm})$, and the absorbed single photon energy $(3.49 \mathrm{eV}$ at $355 \mathrm{~nm})$ was insufficient to break the polymer backbone bonds directly (3.69 eV for C-C). The photothermal mechanism dominated the laser processing or ablation process of the PET film, and the decomposition of the PET polymer chains was mainly pyrolysis [13,26,33-35]. Secondly, regarding the laser irradiation and photothermal conversion, the PET polymer chains either decomposed into small molecules or short-chain polymers, or recomposed [13,26,36]. At the same time, ambient gases such as oxygen and nitrogen also participated in this 
process. Thirdly, as the temperature changed, thermoplastic PET film melted and solidified, resulting in the formation of bumps around the kerf [13], around which the splatter deposited.
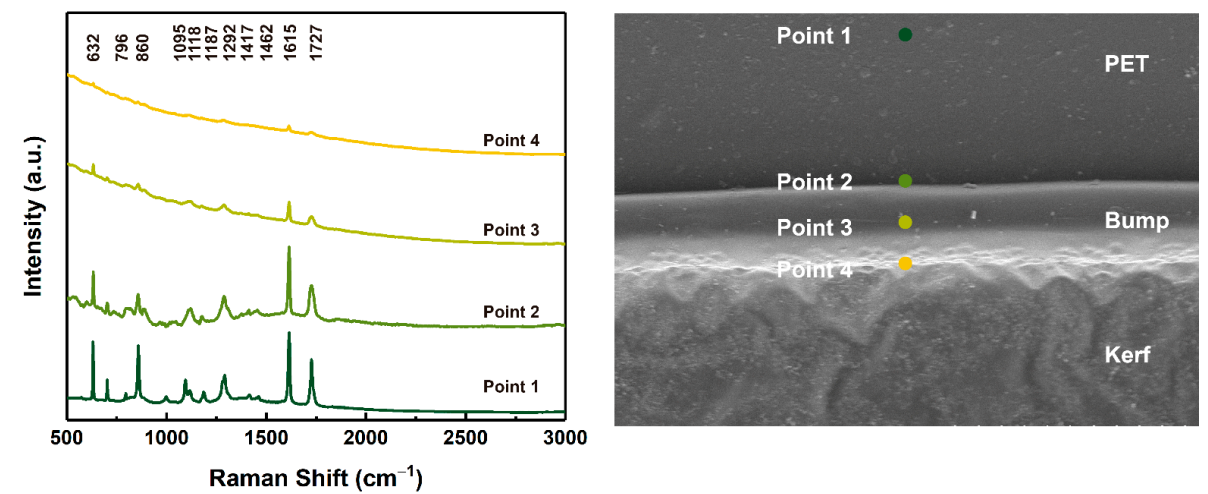

Figure 6. The Raman spectra of PET film after laser processing.

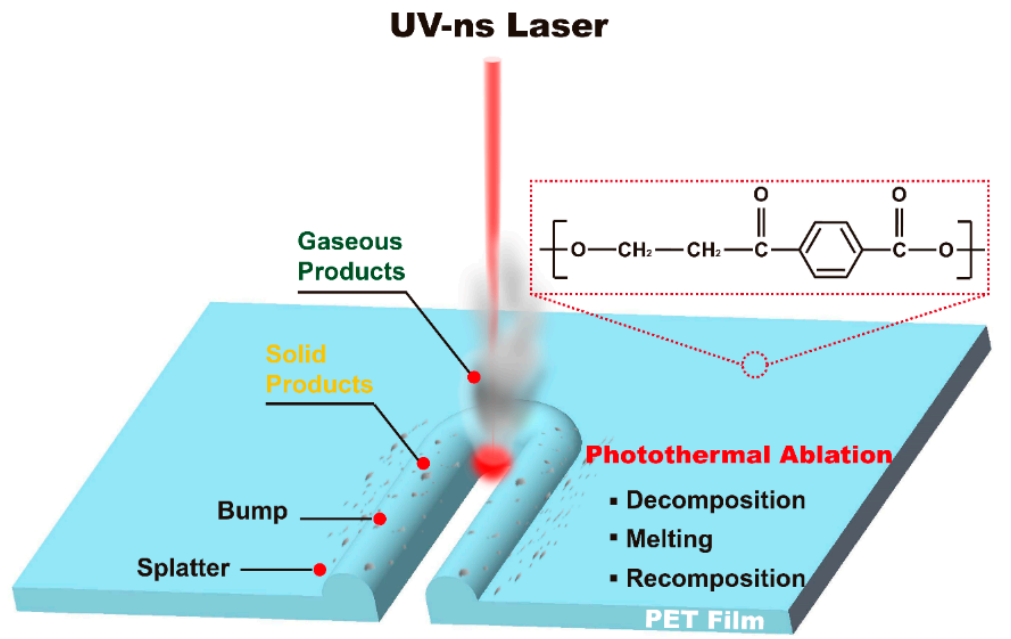

Figure 7. Schematic diagram of the interaction mechanism between the UV-ns laser and the PET film.

\subsection{The Morphology of Features at Different Temperatures}

According to the laser processing mechanism of PET film, it can be seen that the conversion, absorption and transfer of heat as well as the change in temperature had vital influences on this process. Therefore, the external temperature field-assisted laser processing of PET film experiment was designed and performed to investigate the laser processing of PET film at different ambient temperatures and the effects of temperature on the laser processing of PET film, in which single-point laser ablation and line laser ablation were carried out at different temperatures $\left(-25^{\circ} \mathrm{C}, 0^{\circ} \mathrm{C}, 25^{\circ} \mathrm{C}, 50^{\circ} \mathrm{C}, 75^{\circ} \mathrm{C}, 100{ }^{\circ} \mathrm{C}\right)$.

Figures 8 and 9 show the morphologies and sizes of ablation holes in the single-point laser ablation of PET films at different temperatures. As the ambient temperature increased, the so too did the diameter of the ablation hole and processing area. At room temperature $\left(25^{\circ} \mathrm{C}\right)$, the diameter of the ablation hole and processing area was $29.36 \mu \mathrm{m}$ and $45.4 \mu \mathrm{m}$, respectively. When ambient temperature decreased to $0{ }^{\circ} \mathrm{C}$ and $-25^{\circ} \mathrm{C}$, the diameter of the ablation hole was $21.67 \mu \mathrm{m}$ and $20.92 \mu \mathrm{m}$, respectively, and the diameter of processing area was $42.85 \mu \mathrm{m}$ and $36.30 \mu \mathrm{m}$, respectively. When the ambient temperature was above room temperature, the diameter of the ablation hole was $30.42 \mu \mathrm{m}$ at $50{ }^{\circ} \mathrm{C}, 30.26 \mu \mathrm{m}$ at $75^{\circ} \mathrm{C}$ and $24.84 \mu \mathrm{m}$ at $100{ }^{\circ} \mathrm{C}$, respectively, and the diameter of processing area was $47.60 \mu \mathrm{m}$ at $50{ }^{\circ} \mathrm{C}, 49.57 \mu \mathrm{m}$ at $75^{\circ} \mathrm{C}$ and $47.88 \mu \mathrm{m}$ at $100{ }^{\circ} \mathrm{C}$, respectively. As for the $\mathrm{HAZ}$ or the bump, the size was $10.12 \mu \mathrm{m}$ at $-25^{\circ} \mathrm{C}, 9.77 \mu \mathrm{m}$ at $0^{\circ} \mathrm{C}, 12.37 \mu \mathrm{m}$ at $25^{\circ} \mathrm{C}, 10.29 \mu \mathrm{m}$ at $50{ }^{\circ} \mathrm{C}$, $10.11 \mu \mathrm{m}$ at $75{ }^{\circ} \mathrm{C}$ and $12.37 \mu \mathrm{m}$ at $100{ }^{\circ} \mathrm{C}$, respectively. The effect of ambient temperature 
on the size of the HAZ was not obvious. In addition to the change in feature sizes, the morphology of the holes also changed. When the temperature was relatively low $\left(-25^{\circ} \mathrm{C}\right.$, $\left.0{ }^{\circ} \mathrm{C}, 25^{\circ} \mathrm{C}\right)$, the holes were smooth and clean. However, when the temperature increased $\left(50^{\circ} \mathrm{C}, 75^{\circ} \mathrm{C}, 100{ }^{\circ} \mathrm{C}\right)$, wrinkles and debris appeared.

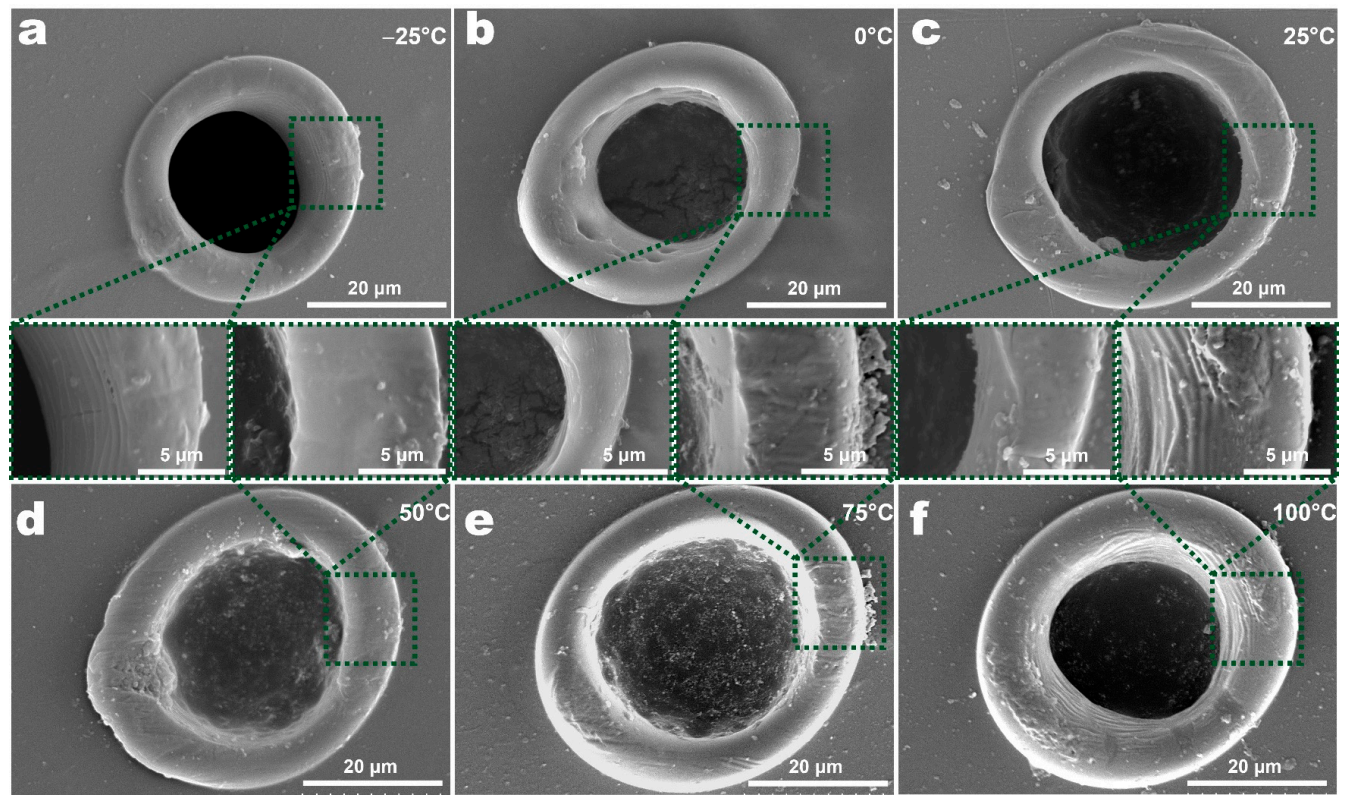

Figure 8. SEM images of holes of PET films at different ambient temperatures in the single-spot laser processing experiment: (a) $-25^{\circ} \mathrm{C}$, (b) $0{ }^{\circ} \mathrm{C},(\mathbf{c}) 25^{\circ} \mathrm{C}$, (d) $50^{\circ} \mathrm{C},(\mathbf{e}) 75^{\circ} \mathrm{C}$, (f) $100^{\circ} \mathrm{C}$.

a

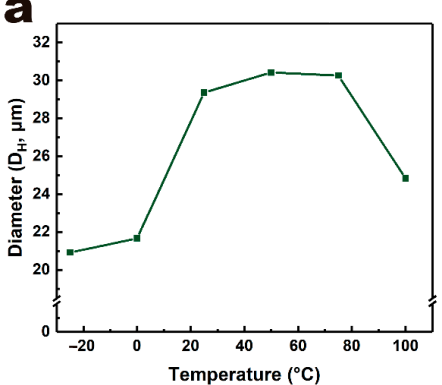

b

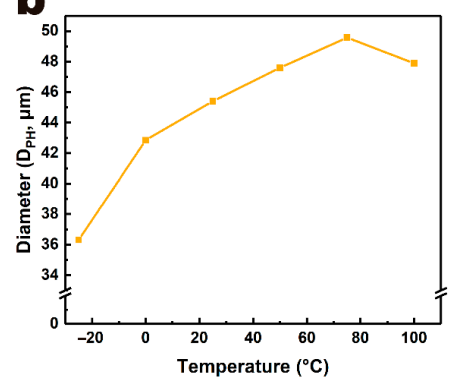

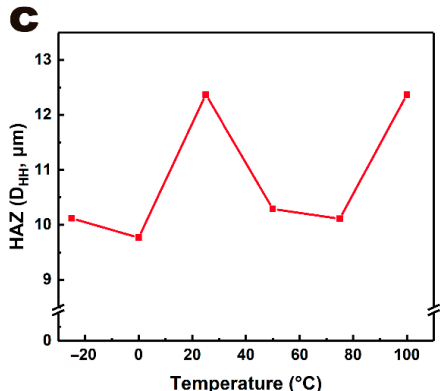

Figure 9. Hole diameter (a), processing area diameter (b) and HAZ (c) of PET films at different ambient temperature in the single spot laser processing experiment.

Figures 10 and 11 show the morphologies and sizes of ablation kerfs in the line laser ablation of PET films at different ambient temperatures. Similar to the single-spot ablation experiment, as the ambient temperature increased, the width of the ablation kerf and processing area also increased. The kerf width was $39.63 \mu \mathrm{m}$ at $-25{ }^{\circ} \mathrm{C}, 48.30 \mu \mathrm{m}$ at $0{ }^{\circ} \mathrm{C}, 45.81 \mu \mathrm{m}$ at $25{ }^{\circ} \mathrm{C}, 69.66 \mu \mathrm{m}$ at $50{ }^{\circ} \mathrm{C}, 77.36 \mu \mathrm{m}$ at $75{ }^{\circ} \mathrm{C}$ and $100.70 \mu \mathrm{m}$ at $100{ }^{\circ} \mathrm{C}$. The processing area width was $71.96 \mu \mathrm{m}$ at $-25^{\circ} \mathrm{C}, 79.84 \mu \mathrm{m}$ at $0{ }^{\circ} \mathrm{C}, 77.43 \mu \mathrm{m}$ at $25^{\circ} \mathrm{C}$, $104.52 \mu \mathrm{m}$ at $50{ }^{\circ} \mathrm{C}, 115.30 \mu \mathrm{m}$ at $75{ }^{\circ} \mathrm{C}$ and $134.73 \mu \mathrm{m}$ at $100{ }^{\circ} \mathrm{C}$. The HAZ width also showed an approximate slow increase trend with increased ambient temperature. The team systematically studied the influences of laser processing parameters (repetition rate, cutting speed and cutting times) on laser processing of PET film [13]. Although optimizing laser processing parameters could improve laser processing to a certain extent, its effect was very limited. Compared to this, adjusting ambient temperature in the current study improved the laser processing process of the PET film more effectively and significantly, which means that this method possesses greater application potential and scope in actual industrial production. 


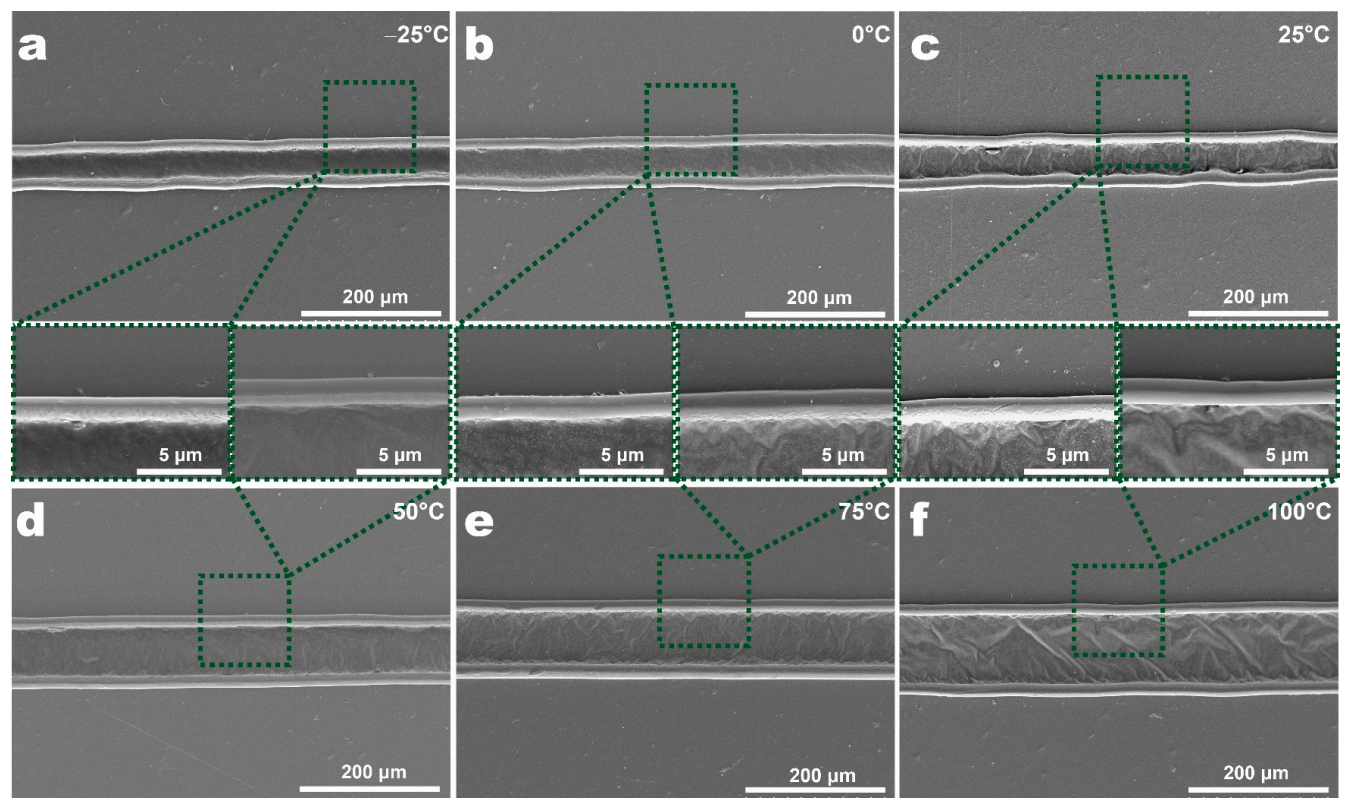

Figure 10. SEM images of kerfs of PET films at different ambient temperatures in line laser processing experiment: (a) $-25^{\circ} \mathrm{C}$, (b) $0{ }^{\circ} \mathrm{C}$, (c) $25^{\circ} \mathrm{C}$, (d) $50{ }^{\circ} \mathrm{C}$, (e) $75^{\circ} \mathrm{C}$, (f) $100{ }^{\circ} \mathrm{C}$.

a

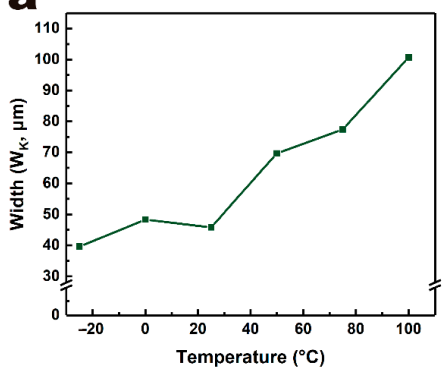

b

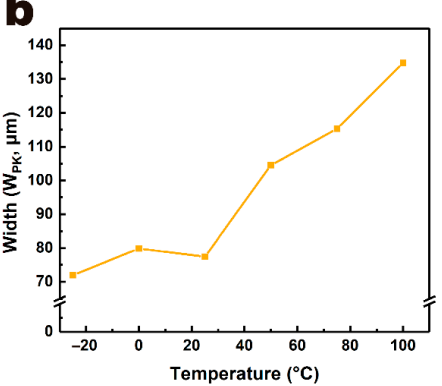

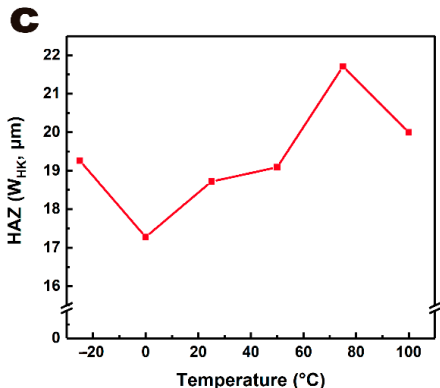

Figure 11. Kerf width (a), processing area width (b) and HAZ (c) of PET films at different ambient temperatures in line laser processing experiment.

\subsection{The Effects of Temperature on Laser Processing of PET Film}

Through the above analysis of the morphologies and sizes of the features (hole and kerf), the effects of ambient temperature on the laser processing of the PET film were revealed. Increasing the ambient temperature promoted the pyrolysis of the PET film and improved laser ablation efficiency, so the sizes of the hole, kerf and processing area increased with the increase in ambient temperature. However, when the ambient temperature was too high, this promotion and improvement might have caused the non-uniform and incomplete decomposition of the PET polymer chain, resulting in debris deposited in the processing area. Indeed, low ambient temperature reduced the HAZ and the thermal effect, while the increase in ambient temperature resulted in an increase in the HAZ and thermal stress, which caused the increase of size of the HAZ or bump and the appearance of wrinkles. The root cause of the above effects on the laser processing of the PET film was that the increase in ambient temperature promoted the heat transfer in the laser processing. The above analysis showed that a proper ambient temperature could not only improve the laser processing efficiency of the PET film, but also ensure good quality [36].

In order to verify and study the effects of ambient temperature on the laser processing of PET film further, the Raman spectra (at HAZ or Bump) of PET films processed at different temperatures were acquired, as shown in Figure 12. As the ambient temperature increased, the characteristic peaks of the functional groups and chemical bonds in the PET film gradually decreased or even vanished. When the ambient temperature was 
low $\left(-25^{\circ} \mathrm{C}, 0{ }^{\circ} \mathrm{C}, 25^{\circ} \mathrm{C}\right)$, the peaks at $632 \mathrm{~cm}^{-1}, 860 \mathrm{~cm}^{-1}, 1187 \mathrm{~cm}^{-1}, 1292 \mathrm{~cm}^{-1}$, etc., were recognizable. However, when the ambient temperature was above $50{ }^{\circ} \mathrm{C}$, these peaks gradually decreased or even disappeared. The difference in Raman spectra of PET films processed at different ambient temperatures proved that the increase in ambient temperature promoted heat transfer during the laser processing, which promoted the pyrolysis of the PET film and made the HAZ increase.

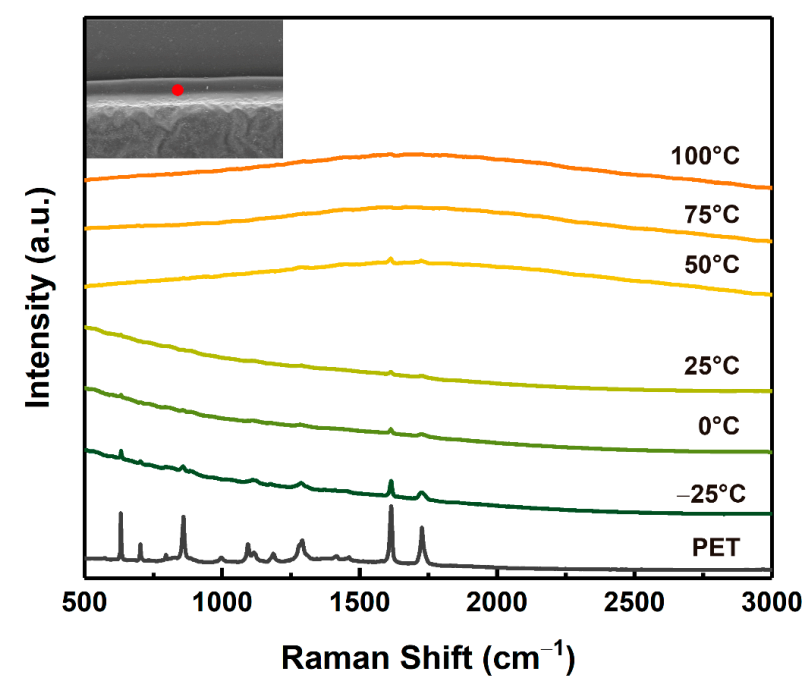

Figure 12. The Raman spectra (at HAZ or bump) of PET films at different temperatures.

\section{Conclusions}

The photothermal ablation mechanism and the effects of ambient temperature on the laser processing of PET film were investigated. According to our studies on the pyrolysis of PET film and the temperature field-assisted UV-ns pulse laser processing, the main conclusions are as follows:

1. When the PET film is almost transparent at the laser excitation wavelength $(355 \mathrm{~nm})$, and the single photon energy at $355 \mathrm{~nm}$ is insufficient to break the polymer backbone bonds directly, the laser processing of PET film is dominated by the photothermal decomposition process (pyrolysis).

2. During the laser processing of PET film, PET polymer chains decompose into small fragments, which recompose, and ambient gases also participate in this process. As the ambient temperature changes, thermoplastic PET film melts, resulting in the formation of a bump. Splatter is deposited in the processing area.

3. An adjustment in ambient temperature affects the laser processing of PET film. An increase in ambient temperature changes the heat transfer and temperature distribution in the laser processing. A low ambient temperature reduces the thermal effect, and an increase in ambient temperature improves the efficiency (kerf width: $39.63 \mu \mathrm{m}$ at $-25^{\circ} \mathrm{C}$, $45.81 \mu \mathrm{m}$ at $25^{\circ} \mathrm{C}, 100.70 \mu \mathrm{m}$ at $100{ }^{\circ} \mathrm{C}$ ) but exacerbates the thermal effect.

This work provides effective methods to study the laser processing mechanism of polymer films as well as an approach to improve the laser processing of polymer films.

Author Contributions: Conceptualization and methodology, C.W.; validation, T.Z.; formal analysis, G.X.; investigation, W.L.; data curation, writing-original draft preparation and writing-review and editing, J.X.; supervision and project administration, Y.R.; resources and funding acquisition, Y.H. All authors have read and agreed to the published version of the manuscript. 
Funding: This work was supported by the National Natural Science Foundation of China (52005206, 51905191), the China Postdoctoral Science Foundation (2020TQ0110), Ministry of Industry and Information Technology's special project for high-quality development of manufacturing industry (TC200H02H), National Key R\&D Program of China (Grant No. 2020YFB2007600), Scientific Research Plan Guiding Project of Hubei Province Education Department (B2019246), Guangdong HUST Industrial Technology Research Institute, Guangdong Provincial Key Laboratory of Digital Manufacturing Equipment (2020B1212060014), Guangdong Basic and Applied Basic Research Foundation (2020A1515011393).

Institutional Review Board Statement: Not applicable.

Informed Consent Statement: Not applicable.

Data Availability Statement: The data presented in this study are available on request from the corresponding author. The data are not publicly available because the data are also part of an ongoing study.

Acknowledgments: The general characterization facilities are provided by the Flexible Electronics Manufacturing Laboratory in Experiment Center for Advanced Manufacturing and Technology in School of Mechanical Science \& Engineering of HUST.

Conflicts of Interest: The authors declare no conflict of interest.

\section{References}

1. Zang, Y.; Shen, H.; Huang, D.; Di, C.A.; Zhu, D. A dual-organic-transistor-based tactile-perception system with signal-processing functionality. Adv. Mater. 2017, 29, 1606088. [CrossRef] [PubMed]

2. Cheng, T.; Zhang, Y.; Lai, W.Y.; Huang, W. Stretchable thin-film electrodes for flexible electronics with high deformability and stretchability. Adv. Mater. 2015, 27, 3349-3376. [CrossRef]

3. Kim, M.P.; Ahn, C.W.; Lee, Y.; Kim, K.; Park, J.; Ko, H. Interfacial polarization-induced high-k polymer dielectric film for high-performance triboelectric devices. Nano Energy 2021, 82, 105697. [CrossRef]

4. Singha, S.S.; Khareb, A.; Joshi, S.N. Fabrication of microchannel on polycarbonate below the laser ablation threshold by repeated scan via the second harmonic of Q-switched Nd:YAG laser. J. Mater. Process. Technol. 2020, 55, 359-372. [CrossRef]

5. Dahotre, N.B.; Harimkar, S. Laser Fabrication and Machining of Material; Springer: Boston, MA, USA, 2001. [CrossRef]

6. Chryssolouris, G. Laser Machining-Theory and Practice, Mechanical Engineering Series; Springer: New York, NY, USA, 1991. [CrossRef]

7. Kamlage, G.; Bauer, T.; Ostendorf, A.; Chichkov, B.N. Deep drilling of metals by femtosecond laser pulses. Appl. Phys. A. 2003, 77, 307-310. [CrossRef]

8. Jia, W.; Yu, J.; Chai, L.; Wang, C.Y. Micromachining soda-lime glass by femtosecond laser pulses. Front. Phys. 2015, 10, 1-4. [CrossRef]

9. Frank, P.; Shaw-Stewart, J.; Lippert, T.; Boneberg, J.; Leiderer, P. Laser-induced ablation dynamics and flight of thin polymer films. Appl. Phys. A 2011, 104, 579-582. [CrossRef]

10. Jiang, H.; Ma, C.; Li, M.; Cao, Z. Femtosecond laser drilling of cylindrical holes for carbon fiber-reinforced polymer (CFRP) composites. Molecules 2021, 26, 2953. [CrossRef] [PubMed]

11. Livingstone, S.A.J.; Chua, K.L.; Black, I. Experimental development of a machining database for the $\mathrm{CO}_{2}$ laser cutting of ceramic tile. J. Laser Appl. 1997, 9, 233-241. [CrossRef]

12. Wu, C.; Li, M.; Huang, Y.; Rong, Y. Cutting of polyethylene terephthalate (PET) film by 355 nm nanosecond laser. Opt. Laser Technol. 2021, 133, 106565. [CrossRef]

13. Ravi-Kumar, S.; Lies, B.; Lyu, H.; Qin, H. Laser ablation of polymers: A review. Procedia Manuf. 2019, 34, 316-327. [CrossRef]

14. Rong, Y.; Huang, Y.; Lin, C.; Liu, Y.; Shi, S.; Zhang, G.; Wu, C. Stretchability improvement of flexible electronics by laser micro-drilling array holes in PDMS film. Opt. Lasers Eng. 2020, 134, 106307. [CrossRef]

15. Beinhorn, F.; Ihlemann, J.; Luther, K.; Troe, J. Micro-lens arrays generated by UV laser irradiation of doped PMMA. Appl. Phys. A 1999, 68, 709-713. [CrossRef]

16. Yong, J.; Fang, Y.; Chen, F.; Huo, J.; Yang, Q.; Bian, H.; Du, G.; Hou, X. Femtosecond laser ablated durable superhydrophobic PTFE films with micro-through-holes for oil/water separation: Separating oil from water and corrosive solutions. Appl. Surf. Sci. 2016, 389, 1148-1155. [CrossRef]

17. Caiazzo, F.; Curcio, F.; Daurelio, G.; Minutolo, F.M.C. Laser cutting of different polymeric plastics (PE, PP and $\mathrm{PC})$ by a CO 2 laser beam. J. Mater. Process. Technol. 2005, 159, 279-285. [CrossRef]

18. Schmidt, H.; Ihlemann, J.; Wolff-Rottke, B.; Luther, K.; Troe, J. Ultraviolet laser ablation of polymers: Spot size, pulse duration, and plume attenuation effects explained. J. Appl. Phys. 1998, 83, 5458-5468. [CrossRef] 
19. Stankova, N.E.; Atanasov, P.A.; Nedyalkov, N.N.; Stoyanchov, T.R.; Kolev, K.N.; Valova, E.I.; Georgieva, J.S.; Armyanov, S.A.; Amoruso, S.; Wang, X.; et al. fs- and ns-laser processing of polydimethylsiloxane (PDMS) elastomer: Comparative study. Appl. Surf. Sci. 2015, 336, 321-328. [CrossRef]

20. Lipperta, T.; Wei, J.; Wokaun, A.; Hoogen, N.; Nuyken, O. Polymers designed for laser microstructuring. Appl. Surf. Sci. 2000, 168, 270-272. [CrossRef]

21. Ahmed, N.; Darwish, S.; Alahmari, A.M. Laser ablation and laser-hybrid ablation processes: A review. Mater. Manuf. Process. 2016, 31, 1121-1142. [CrossRef]

22. Lippert, T.; Yabe, A.; Wokaun, A. Laser ablation of doped polymer systems. Adv. Mater. 1997, 9, 105-119. [CrossRef]

23. Shen, H.; Liu, J.; Chen, Y.; Zhang, J.; Zhang, Z.; Guan, N.; Zhang, F.; Huang, L.; Zhao, D.; Jin, Z.; et al. Investigation on time stability of laser-textured patterned surfaces under different temperatures. Surf. Coat. Technol. 2020, 400, 126225. [CrossRef]

24. Zhou, J.; Xu, R.; Jiao, H.; Bao, J.; Liu, Q.; Long, Y. Study on the mechanism of ultrasonic-assisted water confined laser micromachining of silicon. Opt. Lasers Eng. 2020, 132, 106118. [CrossRef]

25. Bityurin, N.; Luk'yanchuk, B.S.; Hong, M.H.; Chong, T.C. Models for laser ablation of polymers. Chem. Rev. 2003, 103, 519-552. [CrossRef]

26. Kim, W.G.; Kim, D.W.; Tcho, I.W.; Kim, J.K.; Kim, M.S.; Choi, Y.K. Triboelectric nanogenerator: Structure, mechanism, and applications. ACS Nano 2021, 15, 258-287. [CrossRef]

27. Burgess, S.K.; Leisen, J.E.; Kraftschik, B.E.; Mubarak, C.R.; Kriege, R.M.; Koros, W.J. Chain mobility, thermal, and mechanical properties of poly(ethylene furanoate) compared to poly(ethylene terephthalate). Macromolecules 2014, 47, 1383-1391. [CrossRef]

28. Shin, B.; Oh, J.Y. Photothermal and photochemical investigation on laser ablation of the polyimide by $355 \mathrm{~nm}$ UV laser processing. J. Korean Soc. Precis. Eng. 2007, 24, 147-152.

29. Parvinzadeh, M.; Moradian, S.; Rashidi, A.; Yazdanshenas, M.E. Surface characterization of polyethylene terephthalate/silica nanocomposites. Appl. Surf. Sci. 2010, 256, 2792-2802. [CrossRef]

30. Mohan, J. Organic Spectroscopy: Principle \& Application; Mehra: New Delhi, India, 2000.

31. Bistričić, L.; Borjanović, V.; Leskovac, M.; Mikac, L.; McGuire, G.E.; Shenderova, O.; Nunn, N. Raman spectra, thermal and mechanical properties of poly(ethylene terephthalate) carbon-based nanocomposite films. J. Polym. Res. 2015, 22, 39. [CrossRef]

32. Sattmann, R.; Mönch, I.; Krause, H.; Noll, R.; Couris, S.; Hatziapostolou, A.; Mavromanolakis, A.; Fotakis, C.; Larrauri, E.; Miguel, R. Laser-Induced Breakdown Spectroscopy for Polymer Identification. Appl. Spectrosc. 1998, 52, 456-461. [CrossRef]

33. Mansour, N.; Ghaleh, K.J. Ablation of polyethylene terephthalate at $266 \mathrm{~nm}$. Appl. Phys. A 2002, 74, 63-67. [CrossRef]

34. Watanabe, H.; Yamamoto, M. Laser ablation of poly(ethylene terephthalate). J. Appl. Polym. Sci. 1997, 64, 1203-1209. [CrossRef]

35. Klose, S.; Arenholz, E.; Heitz, J.; Bäuerle, D. Laser-induced dendritic structures on PET (polyethylene- terephthalate): The importance of redeposited ablation products. Appl. Phys. A 1999, 69, 487-490. [CrossRef]

36. Wu, C.; Xu, J.; Zhang, T.; Xin, G.; Li, M.; Rong, Y.; Zhang, G.; Huang, Y. Precision cutting of PDMS film with UV-nanosecond laser based on heat generation-diffusion regulation. Opt. Laser Technol. 2022, 145, 107462. [CrossRef] 